\title{
Leakage Reduction in Water Distribution Systems with Efficient Placement and Control of Pressure Reducing Valves Using Soft Computing Techniques
}

\author{
Aditya Gupta \\ Electronics and \\ Communication Dpt \\ Visvesvaraya National \\ Institute of Technology \\ Nagpur, India \\ adityagupta2590@ \\ gmail.com
}

\author{
Neeraj Bokde \\ Electronics and \\ Communication Dpt \\ Visvesvaraya National \\ Institute of Technology \\ Nagpur, India \\ neerajdhanraj@, \\ gmail.com
}

\author{
Dushyant Marathe \\ Electronics and \\ Communication Dpt \\ Visvesvaraya National \\ Institute of Technology \\ Nagpur, India \\ Dushyant.marathe@ \\ gmail.com
}

\author{
Kishore Kulat \\ Electronics and \\ Communication Dpt \\ Visvesvaraya National \\ Institute of Technology \\ Nagpur, India \\ kdkulat@ \\ ece.vnit.ac.in
}

\begin{abstract}
Reduction of leakages in a water distribution system (WDS) is one of the major concerns of water industries. Leakages depend on pressure, hence installing pressure reducing valves (PRVs) in the water network is a successful techniques for reducing leakages. Determining the number of valves, their locations, and optimal control setting are the challenges faced. This paper presents a new algorithm-based rule for determining the location of valves in a WDS having a variable demand pattern, which results in more favorable optimization of PRV localization than that caused by previous techniques. A multiobjective genetic algorithm (NSGA-II) was used to determine the optimized control value of PRVs and to minimize the leakage rate in the WDS. Minimum required pressure was maintained at all nodes to avoid pressure deficiency at any node. Proposed methodology is applied in a benchmark WDS and after using PRVs, the average leakage rate was reduced by $6.05 \mathrm{l} / \mathrm{s}$ $(20.64 \%)$, which is more favorable than the rate obtained with the existing techniques used for leakage control in the WDS. Compared with earlier studies, a lower number of PRVs was required for optimization, thus the proposed algorithm tends to provide a more cost-effective solution. In conclusion, the proposed algorithm leads to more favorable optimized localization and control of PRV with improved leakage reduction rate.
\end{abstract}

Keywords-leakage; pressure management; multiobjective genetic algorithm; pressure reducing valves; water distribution system

\section{INTRODUCTION}

Water losses in pipeline networks can be categorized into (a) apparent losses (such as unauthorized consumption and unmetered bills) and (b) real losses (such as leakages in pipelines and joints). Leakages in pipelines are the main reason for Non-Revenue Water (NRW) losses [11, 13, 19]. Leakages occur due to pipeline deterioration, which is mainly caused by ageing and high pressure. Because of these leakages, extra water has to be pumped out, which increases energy consumption, and consequently, increases the carbon footprint [12]. Nowadays, leakage management is gaining attention among researchers for reducing real losses [14]. Leakage management includes active leakage control, pressure management, and accelerating repair operations. A water distribution system (WDS) is designed according to the peak hour water demand. For the remaining periods when the water demand is less, the water supply system remains under high pressure. Leakages are directly proportional to pressure [18]; therefore, a decrease in the pressure will reduce the leakage rate of WDS. Hence, pressure management has become a crucial part of leakage management, which can be achieved by performing sectorization of the WDS by using isolating valves or by inserting flow and pressure reducing valves (PRVs) in pipeline networks to reduce flow and pressure [2].

Correct placement of these valves along with optimized control is desire so that the WDS will work with a good efficiency. The conservation of mass makes the optimization a nonlinear problem. For optimization, objective functions are required that will satisfy the needful constraints also. During the last decade, many researchers have attempted to optimize the water network using PRVs as a pressure managing tool [6, 16, 26-27, 29]. Mixed integrated nonlinear programing (MINLP) was introduced in [28] for controlling pressure in pipeline infrastructure. A method has been proposed for the localization of valves for controlling pressure in [30] which has low accuracy and low reliability. MINLP was modified as mathematical programming with complimentary constraints (MPCC) in [31]. MPCC also failed to optimize the valve location efficiently [4]. Further research on MPCC was conducted in [24, 25, 32]. In [4], authors proposed a nonlinear program (NLP) algorithm to solve MINLP problems. Binary variables have been proposed to accelerate system performance. The results obtained using this algorithm was more favorable than those obtained using previously used algorithms for leakage reduction; however, it included higher 
computational complexity. In [34], authors proposed an extended model for calibrating optimal operational pressure valve of PRVs using NLP algorithm. The proposed algorithm was applied in EXNET WDS, causing leakage reduction of $5.72 \mathrm{l} / \mathrm{s}$.

Meta-heuristic search was also useful in pressure reduction in pipeline infrastructure [3, 7-8, 33]. In [8], authors proposed a scatter-search meta-heuristic approach for valve location and optimization of the pressure value across the valve. A concept of reference pressure was introduced, which proved to be efficient in determining the locations of PRVs. A scatter-search algorithm was used to determine the optimized pressure value for PRV. Improved results were observed. In [5], authors used a pseudo-valve insertion method (similar to the one in [2]). In this method, a PRV is inserted in the pipeline and parameters are calculated using genetics algorithm (GA). The metaheuristic approach was used to determine the optimized value of PRVs. Simulations were performed on a small-scale WDS. In a real-world scenario, using this approach is difficult in complex pipeline infrastructure because of the large number of variables and computational complexity. Sometimes, the metaheuristic approach may only be able to determine sub-optimal solutions. In [10], authors suggested splitting of the pipeline for pressure management. Splitting results in the optimization of $60 \%$ of nodes at a desired pressure. This method appears suitable for an area having a tank at low height; however, the method was not investigated for systems having reservoirs and areas with tank at higher heights.

Genetic Algorithms (GAs) is a population-based technique that does not require the simplification of the hydraulic model. Hence, GAs are preferred for operational (PRVs location and control and pump optimization) and design optimization of a water distribution system (WDS) compared to classical deterministic optimization techniques. In [23], authors proposed a hybrid objective algorithm (GA and linear programing (LP)) for valve installations and pipe replacements for optimizing a WDS. GAs are used for optimized placement of valves and LP is used to search for an optimal setting of the control valve. In addition, their study explored a trade-off between the number of PRVs and leakage volume. In [21], authors presented a harmony search (HS) model to determine the optimum control setting across the valves. They demonstrated more favorable efficiency with the HS algorithm than the GA for pressure reduction. Optimization of water systems requires multiobjective functions, that is, to determine the optimized value and location of PRVs and to minimize the leakage rate. These objectives attracted researchers [15, 20, 22] to NSGA-II for water infrastructure management. In [17], authors used the multiobjective algorithm to design a realworld WDS. In [1], authors used NSGA-II for reducing leakages in the WDS by using pressure management. NSGA-II was used to determine optimized valve locations. This algorithm uses a population size of 100 with 1000 generations. A higher reduction in the average leakage rate was observed compared with that in [5]. In [4], authors used MPCC and obtained more favorable results than in [1].

Our study delineates the problem of optimization of water pipeline infrastructure by managing pressure using a different and efficient approach. Flow-controlled PRVs were used to modulate pressure. The entire operation was divided into two parts: a) to define reference pressure $\left(\mathrm{P}_{\text {ref }}\right)$ for the calibration of the number of PRVs required along with their location. A new rule was introduced for this calibration. Introduction of this rule led to new PRV location, which led to a higher reduced leakage rate than that with standard techniques used in previous literature; b) after PRV localization, NSGA-II was used to determine the optimized pressure of the valve (first objective) and to minimize the leakage rate (second objective). To apply it in a real-world WDS, different water demand patterns were considered. EPANET [9] was used as a simulation tool along with MATLAB R2015a for calibration, which was performed on a desktop PC (Intel i7 processor with 16 GB RAM).

\section{PRESSURE REDUCING VALVES FOR PRESSURE MANAGEMENT}

A PRV is installed to control the pressure at the downstream end of the valve. PRV operates in three modes: active, closed, and open. The mode of operation depends on upstream and downstream pressures, which can be defined as follows:

$$
\begin{aligned}
& \text { Active; }\left(\mathrm{P}_{\mathrm{dwn}}=\mathrm{P}_{\mathrm{set}}\right) \text { if } \mathrm{P}_{\mathrm{up}}>\mathrm{P}_{\mathrm{set}} \\
& \text { Open; if } \mathrm{P}_{\mathrm{up}}<\mathrm{P}_{\mathrm{set}} \\
& \text { Closed; if } \mathrm{P}_{\mathrm{up}}<\mathrm{P}_{\mathrm{dwn}}
\end{aligned}
$$

where $\mathrm{P}_{\text {up }}$ is upstream pressure; $\mathrm{P}_{\text {set }}$ is operational control setting of PRV; and $\mathrm{P}_{\mathrm{dwn}}$ is downstream pressure.

In the open mode, the valve is fully open. In the closed mode, the valve is fully closed to avoid reverse flow. In the active mode, the valve is partially closed. We aimed to determine the optimized value $\mathrm{P}_{\text {set }}$ for all PRVs present in the system. PRV can be used in three modes.

In the fixed PRV mode, PRV is set to a fixed value of pressure $\left(\mathrm{P}_{\text {set }}=\right.$ constant $)$. This is possibly the simplest mode; however, higher optimization cannot be obtained because water demand pattern changes from time to time. In the second mode, the control value $\left(\mathrm{P}_{\text {set }}\right)$ of the valve changes with respect to time by using a timing device. It is also the simplest and effective method when the demand pattern remains constant and repeats. Such a system fails when the demand pattern changes frequently [1]. The third mode is based on flow modulation. Optimized control value across PRV $\left(\mathrm{P}_{\text {set }}\right)$ was adjusted depending on the flow rate of water. Although flow-controlled PRVs are more complex, higher optimization can be achieved because of more flexibility. Flow-modulated PRVs were used in this study.

\section{A. Leakage calculation}

Leakage rate was calculated for the network by using the pressure-based leakage model. Leakage rate calculations have been adopted from [1]. EPANET [9] was used as a simulating tool for the water network. Optimization and calculation were performed using MATLAB R2015a. According to conservation of mass, continuity at node is expressed as

$$
\Sigma_{j} Q_{i j, k}-K^{*} Q_{r e q, i}-L_{i, k}=0
$$


where $\mathrm{Q}_{\mathrm{i}, \mathrm{j}, \mathrm{k}}$ is flow through pipeline between nodes $\mathrm{i}$ and $\mathrm{j}$ for load condition $K$; $Q_{\text {req,i }}$ is the required flow though node $\mathrm{i}$; and $\mathrm{L}_{\mathrm{i}, \mathrm{k}}$ is the leakage associated with node $\mathrm{i}$.

$$
L_{i, k}=C_{L} * L_{i} * P_{i, k}^{Y}
$$

where $C_{L}$ is the coefficient of leakage per unit length of the link to service pressure; $\mathrm{L}_{\mathrm{i}}$ is the total length of pipeline associated with node $\mathrm{i} ; P_{i, k}$ is the pressure of node $\mathrm{i}$ for demand $\mathrm{k}$; and $\gamma$ is the leakage exponential used to define relation between flow from orifice and head difference. Leakage exponential value of 1.18 [2] is observed for cracks in pipe or joints which occurs due to difference in pressure of internal and external pipe. Therefore writers adopted same value i.e. 1.18 for leakage exponential.

Total length of pipeline associated with node $\mathrm{i}\left(\mathrm{L}_{\mathrm{i}}\right)$ can be calculated using

$$
L_{i}=0.5 * \Sigma_{j} L_{i j}
$$
i.

where $\mathrm{L}_{\mathrm{i}, \mathrm{j}}$ is the total length of pipeline connected with node

Head loss can be calibrated as

$$
H_{i j, k}=H_{i, k}-H_{j, k}
$$

where $H_{i j, k}$ is the head loss between node $\mathrm{i}$ and $\mathrm{j} ; H_{i, k}$ and $H_{j, k}$ are the head measured at node $\mathrm{i}$ and $\mathrm{j}$ for load condition $\mathrm{k}$.

Head loss for pipeline using flow values, can be calculated using Hazen-William equations:

$$
H_{i j, k}=10.668 C_{i j}{ }^{-1.85} d_{i j}{ }^{-1.85} l_{i j} Q_{i j, k}{ }^{1.852}
$$

where $C_{i j}=$ Hazen-William coefficient; $d_{i j}$ is the diameter of pipeline; $l_{i j}$ is length of pipeline connected to node $\mathrm{i}$ and $\mathrm{j}$; and $Q_{i j, k}$ is the flow across pipeline for load condition $\mathrm{K}$.

Head loss across PRV, expressed as

$$
H_{i j, k}=10.668 C_{i j}{ }^{-1.85}\left(v_{i j . k} d_{i j}\right)^{-1.85} l_{i j} Q_{i j, k}{ }^{1.852}
$$

where $v_{\mathrm{ij} . \mathrm{k}}$ is the diameter multiplier when valve is present, during active mode $v_{\mathrm{ij} . \mathrm{k}}$ varies between 0 to $1 \quad\left(0<\mathrm{v}_{\mathrm{ij.k}}<1\right)$ and for open mode $v_{\mathrm{ij} . \mathrm{k}}$ is $1 ; Q_{i j, k} \geq 0$, it means reverse flow of water is not allowed.

The limitations associated with (9) is that, it can't be used during case of close mode when the value of $v_{i i}$ becomes 0 . To overcome from this drawback, authors in [34] have modified the existing model used for calculating head losses under the presence of PRVs, introducing new mathematical equations for calculating head loss in all three operational mode of a PRV. For this study we have also adopted the extended model propped in [34]. Adopting this model $H_{i j, k}$ can be calibrated as

$$
H_{i j, k}=\max \left(0, \mathrm{H}_{\mathrm{i}, \mathrm{k}}-\mathrm{H}_{\mathrm{j}, \mathrm{K}}\right)=10.668 C_{i j}^{-1.85}\left(v_{i j . k} d_{i j}\right)^{1.85} l_{i j} Q_{i j, k}{ }^{1.852}
$$

This PRV model can able to describe all three operation modes i.e. open, close and active, which is required during optimization the pressure reduction process.

Now using the value of head, pressure at node $i$ is calibrated using:

$$
P_{i, k}=H_{i j, k}-e e_{i}
$$

where ele $_{i}$ represents elevation at node $\mathrm{i}$; and $\mathrm{P}_{\mathrm{i}, \mathrm{k}}$ is the value of pressure at node $\mathrm{i}$ for load condition $\mathrm{k}$.

\section{B. Pressure Reducing Valve localization}

In [8], authors introduced the concept of reference pressure to restrict candidate valve locations to a set of pipelines. Our study also uses the reference pressure technique for valve localization. Pressure was considered for an average load condition. Consider $\mathrm{G}$ is set of the entire pipeline present in WDS. A subset $G_{v}\left(G_{v} \in G\right)$ is derived, which belongs to pipeline for PRV candidate. $\mathrm{N}$ is the set corresponding to node. $\mathrm{N}_{1}\left(\mathrm{~N}_{1} \in \mathrm{N}\right)$ is subset of $\mathrm{N}$, which represent the node where pressure exceeds the reference pressure. $\mathrm{N}_{2}\left(\mathrm{~N}_{2} \in \mathrm{N}\right.$ and $\mathrm{N}_{2}=\mathrm{N}-\mathrm{N}_{1}$ ) is also subset of $\mathrm{N}$, whose pressure is below reference pressure. If node $\mathrm{i}$ belongs to subset of $\mathrm{N}_{2}$ and node $\mathrm{j}$ belongs to $N_{1}$, then $G_{v}$ is the subset of pipeline for PRV candidate between node $\mathrm{i}$ and $\mathrm{j}$, is expressed as.

$$
\text { Rule 1. if } \mathrm{N}_{\mathrm{j}}>\mathrm{P}_{\text {ref }} \text { and } \mathrm{N}_{\mathrm{i}}<\mathrm{P}_{\text {ref }}
$$

where $\mathrm{N}_{\mathrm{i}}$ and $\mathrm{N}_{\mathrm{j}}$ is the pressure at node $\mathrm{i}$ and $\mathrm{j}$.

The reference pressure was selected during valve localization operation (using (12)). The reference pressure varied over a range to determine different values of $G_{v, n}\left(G_{v, n}\right.$ represents the number of candidate valve locations for a current value of $P_{\text {ref }}$ ). Pressure value corresponding to a minimum value of $G_{v, n}$ was selected as the reference pressure.

The (12) rule proposed, in [8] suffered from the drawback that, sometimes pressure difference between nodes $\mathrm{N}_{\mathrm{i}}$ and $\mathrm{N}_{\mathrm{j}}$ was slightly high. However, this location was not considered for PRVs localization because pressure was above $P_{\text {ref }}$ for both the nodes. If we were able to cut this excess pressure difference between node $\mathrm{N}_{\mathrm{i}}$ and $\mathrm{N}_{\mathrm{j}}$, this will lead to high reduction in the leakage rate of WDS. To overcome this drawback, a new rule (Rule 2) is introduced for PRV localization, with idea behind is, to also consider the pipeline connecting to nodes $\mathrm{N}_{\mathrm{i}}$ and $\mathrm{N}_{\mathrm{j}}$ as PRV candidate $(\mathrm{Gv})$, which have pressure difference (between $\mathrm{N}_{\mathrm{i}}$ and $\mathrm{N}_{\mathrm{j}}$ ) more than predefined threshold value.

$$
\text { Rule 2. if } \mathrm{N}_{\mathrm{j}}-\mathrm{N}_{\mathrm{i}}>0.1 \times \mathrm{P}_{\text {ref }}
$$

To make this threshold as WDS dependable, the threshold $\left(\geq 0.1 \times \mathrm{P}_{\text {ref }}\right)$ is decided in accordance with reference pressure of existing WDS. If we lower down the threshold ( $5 \%$ of $\left.\mathrm{P}_{\text {ref }}\right)$ value, then number of PRV candidate will get increase, therefore threshold is decided as $10 \%$ of reference pressure, to minimize number of PRV candidate. Rule 2 is applied to the WDS, after Rule 1, for the localization of PRVs candidates.

\section{MULTI-OBJECTIVE GENETIC ALGORITHM FOR VALVE OPTIMIZATION}

The optimal value of PRV was calibrated using the multiobjective GA. We aimed to determine the optimized control value of the PRV with minimum leakage rates in the WDS. After optimization, every node present in the system should maintain minimum pressure $\left(\mathrm{P}_{\min }\right)$ to avoid pressure deficiency at any node. The multiobjective GA was implemented using a function in MATLAB given by: 


$$
\text { [P,leak_val]=gamultiobj(FF,Nv,[],[],[],[], } \left.\mathrm{P}_{\mathrm{mi}}, \mathrm{P}_{\mathrm{ma}}\right)
$$

Where $\mathrm{Nv}$ is 1 (number of variables); $P$ is the pressure control value across PRV $\left(\mathrm{P}_{\text {set }}\right)$ and varies from $\mathrm{P}_{\mathrm{mi}}$ and $\mathrm{P}_{\mathrm{ma}}$; FF is fitness function; and leak_val stores the leakage value in $1 / \mathrm{s}$ corresponding to $\mathrm{P}_{\text {set. }}$.

Fitness function includes two objective functions named as f1 (first) and $\mathrm{f2}$ (second). The first objective (f1) was to determine the optimized pressure value $\left(\mathrm{P}_{\mathrm{set}}\right)$ of PRV.

$$
\min \mathrm{fl} 1=\sum_{\mathrm{i}=1}^{\mathrm{N}_{s}} \mathrm{w}_{\mathrm{k}} \mathrm{C}_{\mathrm{L}} \mathrm{L}_{\mathrm{i}} \mathrm{P}_{\mathrm{i}, \mathrm{k}}^{\mathrm{w}}
$$

subject to:

$$
\begin{gathered}
\mathrm{P}_{\mathrm{i}, \mathrm{k}} \geq \mathrm{P}_{\text {min }} \\
\mathrm{n}_{\mathrm{v}} \leq \mathrm{N}_{\mathrm{v}} \\
\mathrm{H}_{\mathrm{i}, \mathrm{j}, \mathrm{k}}=\mathrm{H}_{\mathrm{i}, \mathrm{k}}-\mathrm{H}_{\mathrm{j}, \mathrm{k}} \\
\mathrm{P}_{\mathrm{mi}} \leq \mathrm{P}_{\mathrm{set}} \leq \mathrm{P}_{\mathrm{ma}}
\end{gathered}
$$

where $\mathrm{P}_{\mathrm{i}, \mathrm{k}}$ is pressure at node $\mathrm{i}$ for load condition $\mathrm{k} ; \mathrm{P}_{\min }$ is the minimum pressure that is required at each node; $\mathrm{n}_{\mathrm{v}}$ represents number of PRV currently being used in WDS; $\mathrm{N}_{\mathrm{v}}$ represents maximum number of PRV allowed to insert in WDS; $\mathrm{P}_{\mathrm{mi}} \& \mathrm{P}_{\mathrm{ma}}$ are the minimum and maximum value allowed across the PRV; $\mathrm{N}_{\mathrm{s}}$ represents number of node present in the system; and $\mathrm{W}_{\mathrm{K}}$ is the value of load (demand multiplier). The algorithm uses population of 50 for individual evolving for 200 generations. Optimized value of PRV has been found out for individual load condition at a time.

The leakage rate (second objective) was calculated for all the optimized values $\left(\mathrm{P}_{\text {set }}\right)$ generated from the first objective (f1). Pressure corresponding to lowest leakage rate was selected.

$$
\min £ 2=\sum_{\mathrm{i}=1}^{\mathrm{N}_{s}} \mathrm{C}_{\mathrm{i}} \mathrm{P}_{\mathrm{i}, \mathrm{k}}^{\mathrm{w}}
$$

where $\mathrm{C}_{\mathrm{i}}\left(\mathrm{C}_{\mathrm{i}}=\mathrm{L}_{\mathrm{i}}{ }^{*} \mathrm{C}_{\mathrm{L}}\right)$ is the flow intensity at node $\mathrm{i}$.

The head and pressure value at each node of the pipeline is required to calibrate the function $\mathrm{f1}$ and $\mathrm{f}$. When the control setting across PRV $\left(\mathrm{P}_{\text {set }}\right)$ changes, the value of the head, pressure and head loss changes across all the nodes and pipeline also change. Calculating the value of the head and pressure for every change in value of $\mathrm{P}_{\text {set }}$ in EPANET is not feasible; therefore within the fitness function, another function was used to calculate hydraulic parameters such as the pressure and head at the WDS nodes for current value of $\mathrm{P}_{\text {set. }}$ Equations 7-11 where used to calibrate the value of pressure at each node, due to variations in value of operational control setting of PRV. The value of $\mathrm{P}_{\text {set }}$ varied from $\mathrm{P}_{\mathrm{mi}}$ to $\mathrm{P}_{\mathrm{ma}}$.

\section{RESUltS AND DISCUSSION}

\section{A. Case study-BenchMark WD}

Optimization operation using PRVs was performed for the water network as shown in Figure 1. This was used as a benchmark in previous studies (Nicolini and Zovatto in [1]; Araujo, Ramos and Coelho in [5]) for pressure management in the WDS by using PRV. The network included 22 nodes, three reservoirs, and 37 links (pipelines).

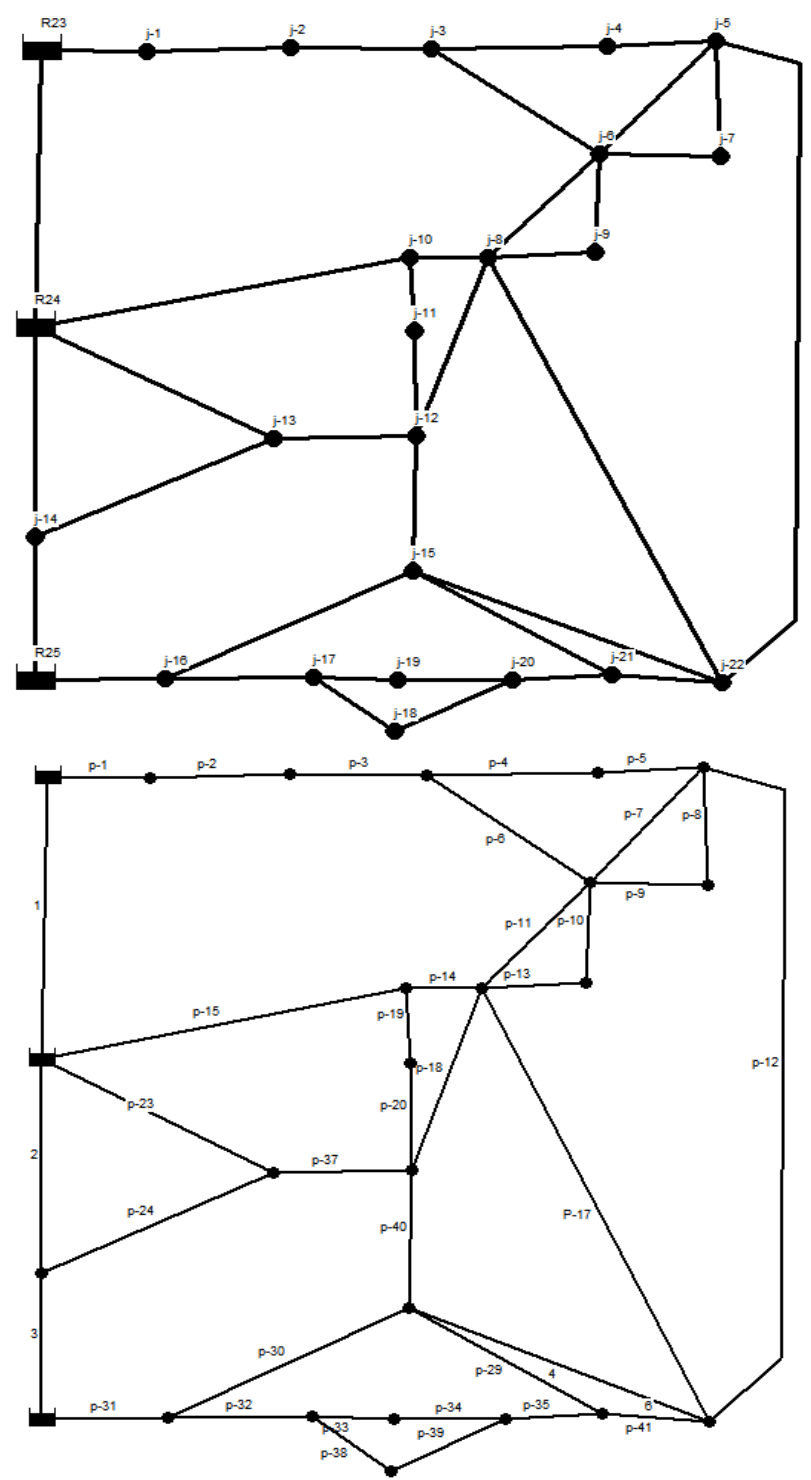

Fig. 1. Layout of water network adopted for the analysis

The height, length, and diameter of the reservoir, node, and pipe were similar to those used in [2]. The elevation of reservoir was set at $56 \mathrm{~m}$. The system had a base demand of $150 \mathrm{l} / \mathrm{s}$. The demand pattern varied with time, which is shown in Table I. The demand varied from 0.6 to 1.4, with an average demand multiplier (load condition) of 1 . The network was simulated in EPANET initially without PRVs. 
Table I shows the leakage rate in the WDS under different load conditions. Using 4-6, the leakage rate was calculated for all load conditions, which varied from 0.6 to 1.4 with an average of 0.98 . For leakage calculations, a typical value of $10^{-5}$ is considered for $\mathrm{C}_{\mathrm{L}}$. Calculated average leakage rate were $29.53 \mathrm{l} / \mathrm{s}$. On considering only three load conditions $(0.6$, 1 , and 1.4) as referred by other authors, the average leakage rate were $29.363 \mathrm{l} / \mathrm{s}$. The profile plot of pressure for different load conditions is shown in Figure 2.

In the profile plot, green color indicates pressure (30-37 $\mathrm{m})$, which is a desired pressure range. Yellow indicates the moderate high pressure zone $(40 \mathrm{~m})$. Red indicates a high pressure zone $(>40 \mathrm{~m})$. During the high peak hour demand (9:00 a.m.), only two nodes indicated high pressure, whereas during the low peak hour demand (12:00 a.m. and 3:00 a.m.), maximum number of nodes were under high pressure. Figure 3 shows the average leakage rate associated with individual nodes. Nodes corresponding to the high leakage rate were 15, 2,3 , and 22 .

TABLE I. LEAKAGE RATE (L/S) FOR DIFFERENT LOAD CONDITION AT DIFFERENT TIME INSTANCES.

\begin{tabular}{|c|c|c|}
\hline Daily Time & $\begin{array}{c}\text { Demand Pattern } \\
\text { (Load condition) }\end{array}$ & Leakage rate (1/s) \\
\hline $12: 00 \mathrm{AM}$ & 0.8 & 30.481 \\
\hline $3: 00 \mathrm{AM}$ & 0.6 & 31.11 \\
\hline $7: 00 \mathrm{AM}$ & 1.0 & 29.261 \\
\hline $9: 00 \mathrm{AM}$ & 1.4 & 27.735 \\
\hline $1: 00 \mathrm{PM}$ & 1.1 & 29.07 \\
\hline Average & $\mathbf{0 . 9 8}$ & $\mathbf{2 9 . 5 3}$ \\
\hline
\end{tabular}

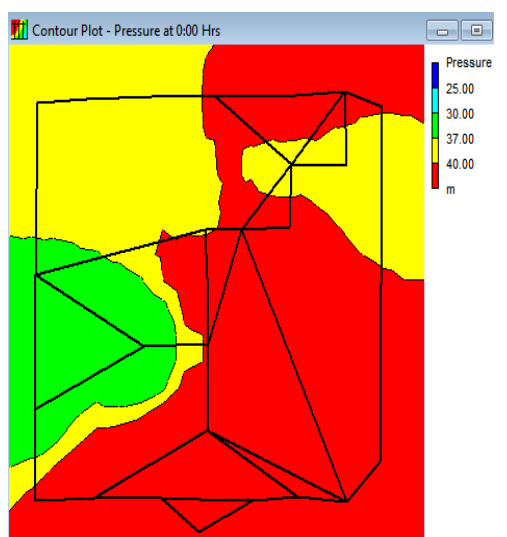

(a) 12:00 AM (0.8)

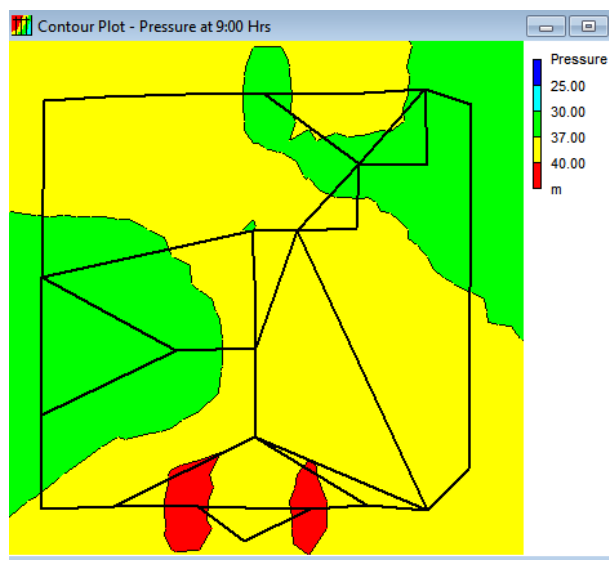

(d) 9:00 AM (1.4)

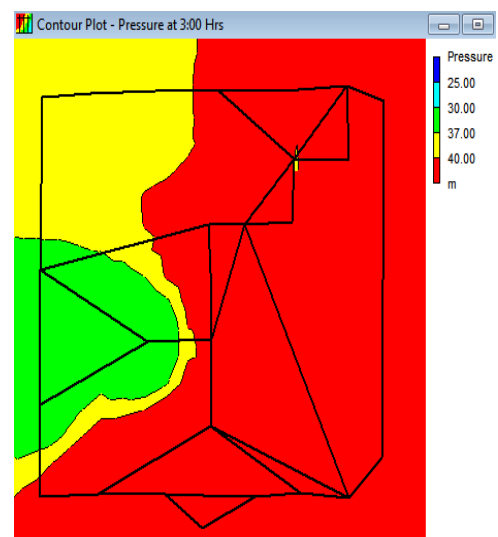

(b) 3:00 AM (0.6)

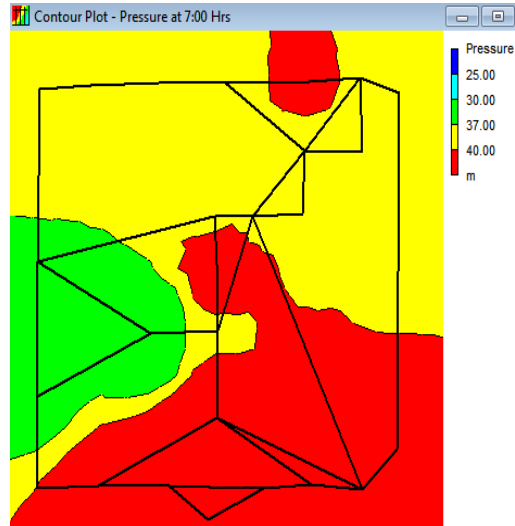

(c) 7:00 AM (1.0)

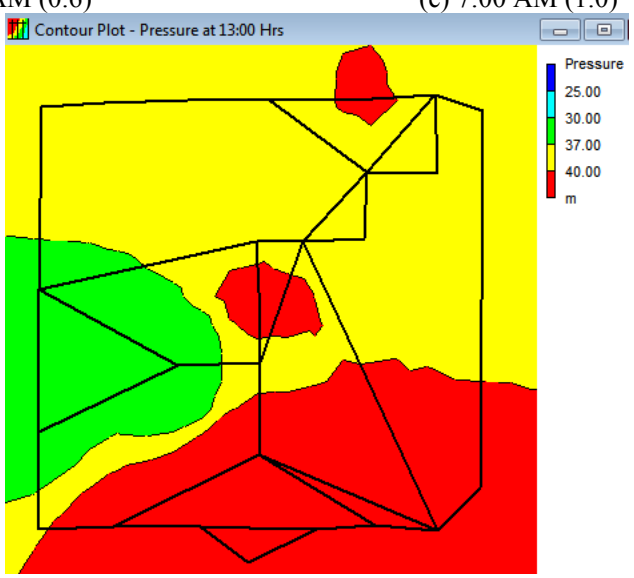

(e) 1:00 PM (1.1)

Fig. 2. Profile plot of pressure with time and the load coefficient

Using 12 and 13 (Rule 1, Rule 2), valve locations were calculated for the average value of the load condition (0.98). Value of reference pressure was selected using (12). The value of references pressure varied from 32 to $40 \mathrm{~m}$. Figure 4 shows a graph between "number of PRV" versus "P ${ }_{\text {ref". }}$

Figure 4 shows that the number of PRV is minimum i.e. 4 , for the reference pressures of 36 and 37; therefore, 36 was selected as the reference pressure. After applying Rule 1 the number of valve location comes out to be 4 . After this, Rule 2 (13) has been applied for finding out additional PRV localization to remove the drawback of Rule $1.3 .6 \mathrm{~m}$ is decided as threshold value for Rule 2, which is $10 \%$ of reference pressure. One additional location is observed for PRV candidate after applying the new rule (13). Thus maximum number of PRV candidate location was fixed to 5 $\left(\mathrm{N}_{\mathrm{v}}\right)$. The locations of valves were at pipe 1, 31, 37, 15 (from Rule 1), and 40 (from Rule 2). When comparing proposed algorithm with reference pressure algorithm proposed in [8], the maximum number of PRV candidate location $\left(\mathrm{N}_{\mathrm{v}}\right)$ has been increased from 4 to 5 . The introduction of new rules has revealed new locations i.e. Pipe-40 for PRV candidate 
location while other 4 PRVs candidate location (p-1, 31, 37, 15) are the same as that suggested from the scheme presented in [8]. The optimized operational value of PRV was obtained using MATLAB. The optimized control pressure of PRV $\left(\mathrm{P}_{\text {set }}\right)$ was between $30\left(\mathrm{P}_{\mathrm{mi}}\right)$ and $35\left(\mathrm{P}_{\mathrm{ma}}\right)$. The value of the minimum desired pressure $\left(\mathrm{P}_{\min }\right)$ at every node was $30 \mathrm{~m}$. MATLAB was also used to calculate the head and pressure at each node (using 7-11) for the pressure value of PRV at $P_{\text {set. }}$. On performing a random check, the values of pressure at node, calculated using 7-11, varied from actual simulated values (from EPANET) with a maximum error of $\pm 1.3 \%$ (i.e. $\pm 0.5 \mathrm{~m})$. GA uses random population for generation of optimal solution. Every time this system generates different optimal solution. As window is already provided for population generation, this minimizes the variations in final optimal solution by $\pm 0.15 \mathrm{~m}$. Therefore NSGA-II has been run for three times and optimal solution is selected by calculating the average of these solutions. Calibrated value of PRVs under different load condition are illustrated in Table II.

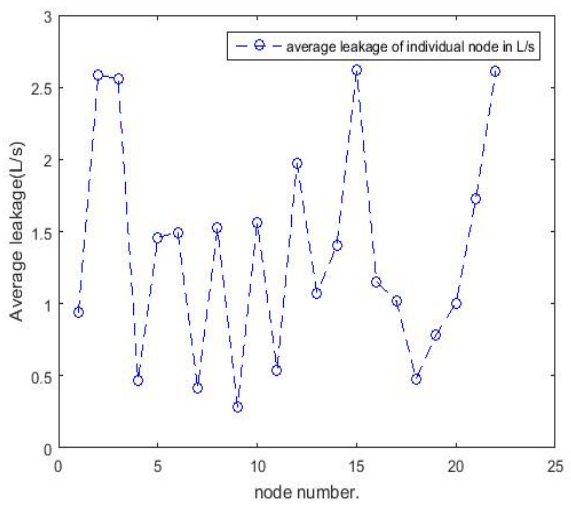

Fig. 3. Average leakage rate $(1 / \mathrm{s})$ of individual nodes

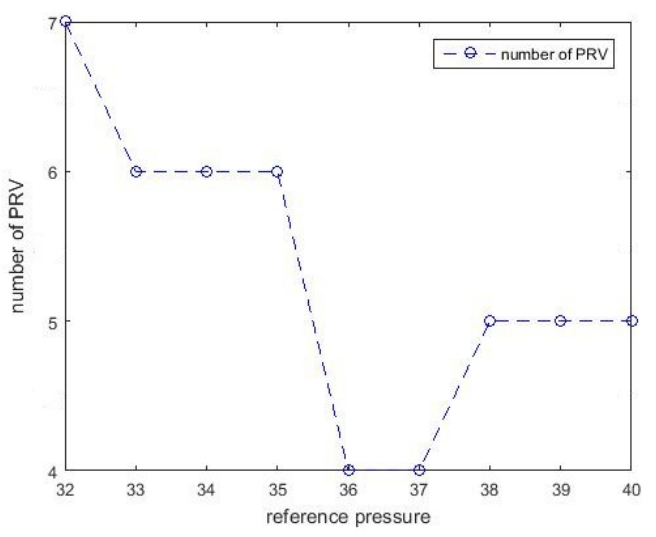

Fig. 4. Numbers of PRVs versus $P_{\text {ref }}$

Initially, two PRVs were installed at pipe 1 and 37 . The third PRV was installed at pipe 31 and fourth at pipe 40 . High optimization was observed after inserting four PRVs. After pressure management, the average leakage rate was reduced to $23.38 \mathrm{l} / \mathrm{s}$ from $29.53 \mathrm{l} / \mathrm{s}$. After adding fifth PRV at Pipe-15 the PRV remains open during load condition of 1 ,
1.1 and 1.4. Whereas during load condition value of 0.6 and 0.8 , it leads to nominal additional average leakage reduction of $0.22 \mathrm{l} / \mathrm{s}$, which is less than $1 \%$ of initial leakage rate. Hence adding fifth PRV can't be efficient as addition of PRV will increase the infrastructure cost of WDS. Thus only four PRVs were used.

TABLE II. OPTIMAL PRESSURE VALUE OF PRV ( $\left.\mathrm{P}_{\mathrm{SET}}\right)$ IN METERS, OBTAINED AFTER APPLYING NSGA-II. HERE DIFFERENT DEMAND PATTERNS (LOAD CONDITIONS) HAVE BEEN CONSIDERED

\begin{tabular}{|c|c|c|c|c|c|}
\hline Number of PRVs & $\mathbf{0 . 6}$ & $\mathbf{0 . 8}$ & $\mathbf{1}$ & $\mathbf{1 . 1}$ & $\mathbf{1 . 4}$ \\
\hline $2(\mathrm{P}-1,37)$ & 30.86 & 31.56 & 32.62 & 32.39 & 34.17 \\
\hline $3(\mathrm{P}-1,37,31)$ & 30.73 & 31.93 & 33.21 & 33.52 & 34.37 \\
\hline $4(\mathrm{P}-37,40,1,31)$ & 31.57 & 32.35 & 33.29 & 33.74 & 34.59 \\
\hline
\end{tabular}

TABLE III. COMPARISON OF AVERAGE LEAKAGE REDUCTION RATE (L/S). THE AVERAGE LEAKAGE RATE HAS CALCULATED FOR DEMAND COEFFICIENT OF 0.6, 1.4 AND 1

\begin{tabular}{|c|c|c|}
\hline Number of PRVs & $\begin{array}{c}\text { Average decrease in } \\
\text { leakage in 1/s (proposed) }\end{array}$ & $\begin{array}{c}\text { Average decrease in } \\
\text { leakage in 1/s ([1]) }\end{array}$ \\
\hline 2 & 4.65 & 3.33 \\
\hline 3 & 5.35 & 4.04 \\
\hline 4 & 6.05 & 4.33 \\
\hline 5 & - & 4.41 \\
\hline $\begin{array}{c}\text { Leakage } \\
\text { reduction (\%) }\end{array}$ & $20.64 \%$ & $16.07 \%$ \\
\hline
\end{tabular}

Table III shows that the leakage reduction rate was higher at every stage than that in studies using the same number of PRVs. The leakage reduction in terms of percentage obtained after using four PRVs from proposed algorithm was more than that observed in [1]; after using 5 PRV, considering load condition of $0.6,1.0$ and 1.4 only. The leakage rate was reduced by $20.64 \%(6.05 \mathrm{l} / \mathrm{s})$, which is more favorable compared with the results obtained in [1]. This proves the robustness of the system. The time taken to calibrate the optimal operational value of PRV for present load condition is 3-5 sec. Hence, the proposed algorithm can be implemented in real time. Considerable reduction in pressure was observed after placing PRV at pipe 40. PRV at this location was not placed in previous studies. This is due to the new rule (Rule 2,13) proposed for localization in this study, which has contributed to the reduction in the leakage rate more than that observed in the previous study.

\section{CONCLUSION}

Our study presents an approach to determine the optimal location and optimized pressure value of PRVs (flowcontrolled) for pressure management. Two rules were implemented for the localization of PRVs using reference pressure. The newly proposed Rule 2 revealed new localization of valves (P-40), which resulted in more favorable leakage reduction due to the reduction of surplus pressure present in the WDS. NSGA-II was implemented with an aim to: a) determine the optimal value of PRVs under different load conditions and b) minimize leakages. Minimum required pressure $\left(\mathrm{P}_{\min }\right)$ is maintained at every demanding node. This avoids pressure deficiency (lower 
pressure than desired) at any node, thus allows WDS to provide services efficiently. The leakage rate was reduced by $6.15 \mathrm{l} / \mathrm{s}(20.82 \%)$ after using the proposed algorithm in a benchmark WDS, considering all the load condition. As shown, the proposed scheme offers an improved performance that also reduces the implementation cost. The proposed system showed successful results for small and medium water networks. Future research should focus on its application in complex networks.

\section{ACKNOWLEDGEMENTS}

The authors would like to express their gratitude to Sudhir Kumar Mishra for revising and correcting the manuscript during the writing period.

\section{REFERENCES}

[1] M. Nicolini, L. Zovatto, "Optimal location and control of pressure reducing valves in water networks" Journal of Water Resources Planning and Management, Vol. 135, No. 3, pp. 178-187, 2009

[2] P. W. Jowitt, C. Xu, "Optimal valve control in water-distribution networks" Journal of Water Resources Planning and Management, Vol. 116, No. 4, pp. 455-472, 1990

[3] Y. Xu, R. Qu, "A hybrid scatter search meta-heuristic for delayconstrained multicast routing problems", Applied Intelligence, Vol. 36, No. 1, pp. 229-241, 2012

[4] P. D. Dai, P. Li, "Optimal localization of pressure reducing valves in water distribution systems by a reformulation approach", Water Resources Management, Vol. 28, No. 10, pp. 3057-3074, 2014

[5] L. Araujo, H. Ramos, S. Coelho, "Pressure control for leakage minimisation in water distribution systems management", Water Resources Management, Vol. 20, No. 1, pp. 133-149, 2006

[6] B. Baumrucker, L. Biegler, "Mpec strategies for optimization of a class of hybrid dynamic systems", Journal of Process Control, Vol. 19, No. 8, pp. 1248-1256, 2009

[7] D. A. Savić, G. A. Walters, "Integration of a model for hydraulic analysis of water distribution networks with an evolution program for pressure regulation", Computer Aided Civil and Infrastructure Engineering, Vol. 11, No. 2, pp. 87-97, 1996

[8] S. Liberatore, G. Sechi, "Location and Calibration of valves in water distribution networks vusing a scattersearch meta-heuristic approach", Water Resources Management, Vol. 23, No. 8, pp. 1479-1495, 2009

[9] L. Rossman, EPANET User's Manual. 2000, Risk Reduction Engineering Laboratory, U.S. Environmental Protection Agency, Cincinnati, Ohio, USA

[10] S. Tabraiz, L. A. Qureshi, B. A. Rai, A. Azam, Z. Abbas, "Optimization of water distribution system by split pipe method: a rule of thumb", Journal of Water Supply: Research and TechnologyAqua, Vol. 65, No. 3, pp. 253-265, 2016

[11] A. Lambert, "International report: water losses management and techniques", Water Science and Technology: Water Supply, Vol. 2, No. 4, pp. 1-20, 2002

[12] M. Girard, R. A. Stewart, "Implementation of pressure and leakage management strategies on the Gold Coast, Australia: Case study", Journal of Water Resources Planning and Management, Vol. 133, No. 3, pp. 210-217, 2007

[13] R. S. Mckenzie, H. Mostert, W. Wegelin, "Khayelitsha: Leakage reduction through advanced pressure control", J. Inst. Munic. Eng. S. Africa, Vol. 27, No. 8, pp. 43-47, 2002

[14] M. Farley, S. Trow, A practitioner's guide to assessment, monitoring and control, IWA, London, 2003

[15] R. Farmani, D. A. Savic, G. A. Walters, "Evolutionary multi-objective optimization in water distribution network design", Engineering Optimization, Vol. 37, No. 2, pp. 167-185, 2005
[16] D. Halhal, G. A. Walters, D. Ouazar, D. A. Savic, "Water network rehabilitation with structured messy genetic algorithm", Journal of Water Resources Planning and Management, Vol. 123, No. 3, pp. 137-146, 1997

[17] E. Keedwell, S. T. Khu, "A novel evolutionary metaheuristic for the multi-objective optimisation of real-world water distribution networks", Engineering Optimization, Vol. 38, No. 3, pp. 319-333, 2006

[18] A. O. Lambert, "What do we know about pressure: Leakage relationship in distribution systems?", IWA Conference on System Approach to Leakage Control and Water Distribution Systems Management, Brno Czech Republic, IWA, London, 2001

[19] A. Gupta, . Mishra, N. Bokde, K. Kulat, "Need of Smart Water Systems In India", International Journal of Applied Engineering Research, Vol. 11, No. 4, pp. 2216-2223, 2016

[20] T. D. Prasad, N. Park, "Multiobjective genetic algorithms for design of water distribution networks", Journal of Water Resources Planning and Management, Vol. 130, No. 1, pp. 73-82, 2004

[21] F. De Paola, E. Galdiero, M. Giugni, "A jazz-based approach for optimal setting of pressure reducing valves in water distribution networks", Engineering Optimization, Vol. 48, No. 5, pp. 727-739, 2016

[22] K. Deb, S. Agrawal, A. Pratap, T. Meyarivan, "A fast and elitist multi-objective genetic algorithm: NSGA-II", IEEE Transactions on Evolutionary Computation, Vol. 6, No. 2, pp. 182-197, 2002

[23] E. Creaco, G. Pezzinga, "Multiobjective optimization of pipe replacements and control valve installations for leakage attenuation in water distribution networks", Journal of Water Resources Planning and Management, Vol. 141, No. 3, Art. No. 04014059, 2002

[24] X. Hu, D. Ralph, "Convergence of a penalty method for mathematical programming with complementarity constraints", Journal of Optimization Theory and Applications, Vol. 123, No. 2, pp. 365-390, 2004

[25] S. Leyffer, G. López-Calva, J. Nocedal, "Interior methods for mathematical programs with complementarity constraints", SIAM Journal on Optimization, Vol. 17, No. 1, pp. 52-77, 2006

[26] A. V. Babayan, D. A. Savic, G. A. Walters, Z. S. Kapelan, "Robust least-cost design of water distribution networks using redundancy and integration-based methodologies", Journal of Water Resources Planning and Management, Vol. 1, No. 133, pp. 67-77, 2007

[27] K. Vairavamoorthy, J. Lumbers, "Leakage reduction in water distribution systems: Optimal valve control", ASCE Journal of Hydraulic Engineering, Vol. 124, No. 11, pp. 1146-1154, 1998

[28] K. Hindi, Y. Hamam, "Locating pressure control elements for leakage minimization in water supply networks: An optimization model", Engineering Optimization, Vol. 17, No. 4, pp. 281-291, 1991

[29] B. J. Eck, M. Mevissen, Valve placement in water networks: mixedinteger non-linear optimization with quadratic pipe friction, Report No RC25307 (IRE1209-014), IBM Research, September, 2012

[30] K. Kraemer, S. Kossack, W. Marquardt, "An efficient solution method for the minlp optimization of chemical processes", Computer Aided Chemical Engineering, Vol. 24, pp. 105-110, 2007

[31] A. U. Raghunathan, L. T. Biegler, "Mathematical programs with equilibrium constraints (mpecs) in process engineering", Computers \& Chemical Engineering, Vol. 27, No. 10, pp. 1381-1392, 2003

[32] O. Stein, J. Oldenburg, W. Marquardt, "Continuous reformulations of discrete-continuous optimization problems", Computers \& Chemical Engineering, Vol. 28, No. 10, pp. 1951-1966, 2004

[33] A. Fanni, L. Liberatore, G. M. Sechi, M. Soro, P. Zuddas, "Optimization of water distribution systems by a tabu search metaheuristic", in: Computing tools for modeling optimization and simulation, Vol 1, Kluwer, Boston, MA, pp 279-298, 2000

[34] P. D. Dai, P. Li, "Optimal pressure regulation in water distribution systems based on an extended model for pressure reducing valves", Water Resources Management, Vol. 30, No. 3, pp. 1239-1254, 2016 